Volume (3) No. (3) 2020

ADHD is like a bat - it is neither a bird nor an animal: Saudi Parents' Discourses About Attention Deficit Hyperactivity Disorder

Rabab Saleh Alharbi 


\title{
ADHD is like a bat - it is neither a bird nor an animal: Saudi Parents' Discourses About Attention Deficit Hyperactivity Disorder
}

\author{
Rabab Saleh Alharbi, Researcher, University of Ottawa, Canada \\ alharbirabab@gmail.com
}

Received in 25th January 2020

Accepted in 1st May 2020

\begin{abstract}
ADHD is the most commonly diagnosed neurobehavioral disorder among children. While ADHD in Western countries has long been recognized and increasingly diagnosed in recent years, there is a growing recognition of this disorder as a significant cross-cultural phenomenon. Saudi studies to date vary in their estimation of prevalence of ADHD, with overall prevalence estimated to be between $3.5 \%$ and $6.5 \%$, while the worldwide prevalence of ADHD is $5.29 \%$. This study uncovers the lived experience of parents with a child who has had an ADHD diagnosis in Saudi Arabia, and examines how their experiences can be recognized in relation to the multiple and competing discourses of ADHD that frame their daily lives. Which discourses do parents draw upon - and reinforce - as they describe their experiences of ADHD, and which discourses do they resist? This study carried out in-depth interviews with seven Saudi parents who have at least one child diagnosed with ADHD, or any of its subtypes, between the ages of two and 11. Foucauldian discourse analysis (FDA) is applied in analyzing parental ADHD discourses, uncovering how these parents made sense of ADHD pre-and post-diagnosis. Four main discourses emerged in the process: normal behavior (pre-diagnosis), supernatural/religious, medical, and social environment (post-diagnosis). This paper also emphasises that the causes of ADHD must be considered in the wider context of misconceptions and uncertainty among Saudi parents. All the participants in this research were influenced by a combination of discourses in their attempts to make sense of their children's symptoms.
\end{abstract}

Keywords: ADHD, Attention Deficit Hyperactivity Disorder, Saudi Parents 


\section{Introduction}

While ADHD in Western countries has long been recognized and increasingly diagnosed in recent years, there is a growing recognition of this disorder as a significant cross-cultural phenomenon (Hinshaw et al., 2011). ADHD is the most commonly diagnosed neurobehavioral disorder among children (Mannuzza et al., 2003; Zaki, 2013). While there is some variation in prevalence studies, meta-regression analyses have estimated the worldwide prevalence of ADHD at 5.29\% (Polanczyk et al., 2007). To date, Saudi studies vary in their estimation (Zaki, 2013). For example, Al Hamed et al. (2008) investigated the prevalence of ADHD among school-age boys in Dammam city estimating it at 6.5\%. Jenahi et al. (2012) studied 1009 female pupils in Al-Khobar city and estimated prevalence at $3.5 \%$. Polanczyk et al. $(2007,2014)$ argue that variability in ADHD prevalence data between studies is mostly explained by different methodological factors such as the source of the information, or diagnostic criteria. Meanwhile, research in the West finds a relationship between ADHD symptoms and poor educational outcomes, learning difficulties and absenteeism at school (Barry et al., 2002), antisocial behavior, crime, substance abuse, car accidents, and difficulty in finding or keeping a job (Hammond, 2008).

ADHD is a neurobehavioral condition characterized by inattention and/or hyperactivity and impulsivity (Nigg, 2006). ADHD symptoms are defined in the Diagnostic and Statistical Manual of Mental Disorders (fifth edition, or DSM-5; American Psychiatric Association [APA] 2013). Saudi Arabia uses the APA's definition and criteria in assessing ADHD.

Many studies of mental health disorders situate them firmly within the realm of medicine. The logic is that the same kinds of processes that cause physical diseases also underlie mental health illness; hence they can be treated or cured in the same way - by medical interventions (Southall, 2007). This hypothesis has become widely accepted by medical authorities in the case of ADHD. The neuro-anatomy of ADHD in medical discourse focuses on abnormal development of key brain regions: the orbital prefrontal cortex, the basal ganglia and cerebellum (Arnsten, 2009). Nigg (2006) summarizes the 
multiple causations of ADHD in terms congruent with the discourse of neurochemistry, presented in vernacular language that can be understood by a lay audience. In this book and others of its kind, readers are presented with hard evidence, given the names of specific organs, chemicals, and shown the ways in which deficits appear as ADHD symptoms; there is no clouding of the discussion by subjectivist explanations drawing on other discourses. Nevertheless, the medical account of ADHD is far from being a unified discourse; debate about its etiology, diagnosis and treatment continues (Hammond, 2008; Visser \& Jehan, 2009). Meanwhile, opponents of the medical discourse have developed alternative approaches to explaining and treating ADHD, such as the social construct account (Conrad \& Bergey, 2014; Timimi \& Taylor, 2004) and the psychodynamic account (Conway, 2012). Both see the origin of the problem in factors external to the child.

Social construct advocates suggest that not only is ADHD a 'contaminated and misleading' mainstream notion (Timimi \& Taylor, 2004, p.8) but also a 'culture-bound syndrome limited to the U.S. or English-speaking countries' (Conrad \& Bergey, 2014). They propose that the prevalence of ADHD in recent years is a result of 'the demands of modern culture' (Hinshaw \& Scheffler, 2014; Timimi \& Maitra, 2009). It is argued that biological theories about ADHD are lacking a broader cultural perspective because they view ADHD symptoms as appearing only within the child or his/her immediate environment (Timimi \& Taylor, 2004). They suggest that ADHD is an outcome of radical changes in family structure and parenting styles (e.g., Timimi \& Taylor, 2004). For others, ADHD reflects the state of modern public education, in which crowded classrooms and overwhelmed teachers become intolerant of children who cannot focus or sit still (e.g. Hinshaw \& Scheffler, 2014). Social construct approaches advocate replacing medical interventions with educational and cultural modifications (e.g., Conrad \& Schneider, 2010) and emphasize that children with ADHD need attention, improved parenting, better schooling, and environmental changes (Hansen, 2014; Jacbos 2002). 
The psychodynamic perspectives refer to the study of forces in the social environment that might affect human behaviors and emotions and the ways in which they might relate to early experience (Conway, 2012; Rafalovich, 2001). Psychodynamic studies of the diagnosis of ADHD are rooted in two major concepts: ego disturbance and object relations. Proponents of ego disturbance attribute the symptoms of ADHD to difficulties in a child's ego functioning affecting their ability to synthesize, organize and integrate their experiences (Gilmore, 2000, 2002), to manage their relationship to time, and sustain their attention on a given object (Jones, 2011). This may result in hyperactive behaviors in the expression of their feelings (Jones \& Allison, 2010). Another psychodynamic perspective attributes ADHD symptoms to early issues in object relations (Conway, 2012) including disturbances in interactions with family members, and experiences of early trauma (e.g. Cione et al., 2011; Leuzinger-Bohleber et al., 2011). Ladnier and Massanari (2000) analyzed the histories of 50 people diagnosed with ADHD and found evidence of disturbances in object relations in the first two years of life. This interferes with the development of a healthy attachment to the mother figure, resulting in ADHD-like symptoms (Ladnier \& Massanari, 2000). From the object relations perspective, an intensive, long-term approach is key to working with children with ADHD and their parents in order to lessen the child's ADHD symptoms, decrease parental anxiety and improve success rates of treatment (Cione et al., 2011; Widener, 1998).

Parents' perceptions and beliefs regarding the nature of ADHD symptoms and its etiology has a significant influence on referral, service utilization and treatment uptake (Lawton et al., 2014; Maniadaki et al., 2007). In a study of 119 Iranian parents and their children with ADHD, Ghanizadeh (2007) found that the parents were poorly informed about ADHD and had misconceptions about its causes. Gidwani et al., (2006) conducted a cross-cultural study in Puerto Rico, Central and South America, and North America, concluding that expectations for developmentally appropriate behavior vary across ethnic groups. Furthermore, parents who do not accept medical accounts of ADHD may choose services that better suit their understanding of the problem; this may include seeking advice from a spiritual leader (Yeh et al. 2005). 
ADHD was first acknowledged in Saudi studies when Abdur-Rahim et al. (1996) investigated the services offered in a child psychiatric clinic in Riyadh. The authors used semi-structured interviews and a functioning scale to assess 199 children aged 14 years or younger over a six-year period. Although this study examined children's psychological problems in general, it highlighted the prevalence of ADHD within this group (12.6\% were diagnosed with ADHD). Most Saudi ADHD studies in subsequent years have been quantitative (e.g. Taleb and Farheen, 2013; Jenahi et al., 2012). Others have assessed knowledge or perceptions of ADHD among Saudi parents (Zaki, 2013; Alamiri and Faulkner, 2010), concluding that parents have basic knowledge of ADHD, but little understanding of causes and possible interventions.

However, as ADHD is not a homogenous disorder, parents of children with the combined presentation of ADHD (both inattention and hyperactive symptoms) may face more challenges than those of children with either inattentive or hyperactiveimpulsive presentations (Tzang et al., 2009); the same is true when other disorders are diagnosed alongside ADHD (McIntyre \& Hennessy, 2012).

This paper is based on the author's doctoral research, which uncovers the lived experience of parents of children with an ADHD diagnosis in Saudi Arabia, and asks how their experiences can be understood in relation to the multiple and competing discourses of ADHD that frame their daily lives. Which discourses do parents draw upon - and reinforce - as they describe their experiences of ADHD, and which discourses do they resist?

The paper does not debate the 'truth' of ADHD, as others have (Saul, 2014; Visser \& Jehan, 2009), or accept claims that ADHD is purely a social construct or a myth (Armstrong, 2017). As Timimi and Taylor (2004, p.9) state, 'The professional task is to understand how genetic and social influences interact, not to simplify into a polemic'. From a theoretical point of view, Foucault indicates that it is not helpful to focus on the truth or the ontological foundations that may legitimate it (Foucault, 1972). Instead, one should question its discursive formation, in order to reveal it or modify it (Foucault, 1972). Thus, the objective of the present research is to consider the 
discourses which shape Saudi parents' perceptions and approaches to ADHD symptoms in their children, influencing both perceptions of ADHD and potential courses of action to address it. This paper asks: what are the experiences of Saudi parents of children with ADHD and what is the influence of Saudi society on them and on understandings of ADHD itself as 'a system of formation' (Foucault, 1972, p.205)?

\section{Methodology}

To explore the discourses related to ADHD in Saudi Arabia, Foucauldian discourse analysis (FDA) formed the analysis of how ADHD is discursively constructed through what parents say about their experience of learning about the disorder and their endeavors to get help for their child or children.

Foucault acknowledges the uncertainty of 'truth' and the pluralism of meaning in analyzing discourse, underscoring the message that literal meaning should not be the focus for discourse analysts. This is not to suggest that 'anything goes'; on the contrary, it is an invitation, to use a Foucauldian term, to create a space to be able to rethink. What is important, then, is not what the discourse means literally, but what it conceals, and what it achieves. The point of this approach is to "[concentrate] on the relations of power and knowledge in modern society" (Dreyfus and Rabinow, 1982, p.105) and to expose the conditions of stability, presence, authority, and power relations when analyzing social institutions (Said, 1978). A commitment to revealing underlying forces as described by Said makes the use of FDA particularly appropriate for the purpose of this research: to explore the discourses regarding ADHD emerging from the Saudi parents' interviews, and to assess their implications for understanding and treating ADHD.

FDA is concerned with the role of language in the formation of social life. Foucault (1972) describes discourse as 'practices that systematically form the objects of which they speak' (p.42). Discourse, then, involves social and ideological practices which not only influence how individuals think, interact, and behave (Baxter, 2002), but also form the reality of what they say. Parker (1992) describes the notion of 
discourse, in a Foucauldian sense, as facilitating and limiting, enabling and constraining what can be said, by whom, where and when.

Given that FDA acknowledges the link between discourse and power, and questions the subject positions occupied within discourse and the implications of discourse for subjectivity and experience (Willig, 2008), it provided a fitting theoretical framework for the present research. Throughout Foucault's writings, he is reluctant to outline his approach in details (Tamboukou, 1999). He states, 'I take care not to dictate how things should be' (Foucault, 1994, p.288). This reticence has generated various guidelines by subsequent discourse analysts. Willig's method (2008), in six stages, poses the following questions:

- What are the ways in which the discursive object is constructed?

- What are the various discursive constructions of the object within wider discourses?

- What are the functions and benefits of constructing the object in a specific way?

- What are the different subject positions that these discourses offer?

- What is the relationship between discourse and practice?

- What is the relationship between discourse and subjectivity?

\section{Data Collection and Participant Recruitment}

For this study, in-depth interviews were carried out with seven Saudi parents (two of them a married couple and parents of three children with an ADHD diagnosis) who have at least one child diagnosed with ADHD, or any of its subtypes, between the ages of two and 11. Recruiting participants was challenging; initial plans had to be altered in order to find parents willing to be interviewed.

The plan was to interview parents from Jeddah whose children were diagnosed with ADHD between the ages of seven and 14. I planned to recruit them through three public elementary schools in Jeddah offering ADHD programs. In Saudi Arabia, girls 
are educated separately from boys and by female teachers only. As a woman, I could not approach boys' schools for this study.

In each of the three girls' schools I visited, after my meeting with the school principal, I met the school counselor and invited her to distribute the recruitment text to parents of children with ADHD. Out of the three schools, only one mother responded, indicating that both she and her husband would be willing to participate. I also approached four clinicians to invite them to distribute my contact details to parents of children with ADHD. They all promised to do so, but no parents responded via this route.

I then searched for parents of children with ADHD on social media platforms. I used the search terms "ADHD", "parent of children with ADHD", and "parent of children with ADHD groups" and expanded the age criterion to children under 14, with no minimum age. I found an account of a mother of a child diagnosed with ADHD, named Aliya (not her real name). I contacted her privately and learned that she had created a social media mothers' group for those with children with an ADHD diagnosis. I invited her to share the recruitment text with members from her group. She accepted and two mothers contacted me via WhatsApp. They agreed to participate, choosing a telephone interview. Prior to their interview, they signed a consent form and returned it to me.

I contacted Aliya again to explain that I had recruited only three parents from Jeddah and request her help in sharing the recruitment text with all the members in her group. This yielded three more volunteers, who also chose phone interviews. Again, consent forms were completed and returned. 
To protect their anonymity, pseudonyms are used to identify participants.

\begin{tabular}{|c|c|c|c|c|}
\hline \multicolumn{5}{|c|}{ Recruited/interviewed parents of children with ADHD } \\
\hline $\begin{array}{c}\text { Interviewed } \\
\text { Parent }\end{array}$ & $\begin{array}{c}\text { Gender of } \\
\text { child/children }\end{array}$ & Children's age & City & $\begin{array}{c}\text { Parent } \\
\text { pseudonyms }\end{array}$ \\
\hline Father, Mother & $\begin{array}{l}2 \text { girls, } 1 \text { boy (all } \\
\text { diagnosed with } \\
\text { ADHD) }\end{array}$ & $8,10,11$ years & Jeddah & Salem, Sara \\
\hline Mother & A girl & $\begin{array}{c}4 \text { years and } 4 \\
\text { months }\end{array}$ & Jeddah & Farah \\
\hline Mother & A boy & $\begin{array}{c}2 \text { years and } 9 \\
\text { months }\end{array}$ & Jeddah & Fatimah \\
\hline Mother & A boy & $\begin{array}{c}5 \text { years and } 6 \\
\text { months }\end{array}$ & Riyadh & Noof \\
\hline Mother & A girl & $\begin{array}{c}6 \text { years and } 6 \\
\text { months }\end{array}$ & Riyadh & Rama \\
\hline Mother & A girl & $\begin{array}{c}7 \text { years and } 10 \\
\text { months }\end{array}$ & Alsulayyil & Rose \\
\hline
\end{tabular}

\subsection{Analysis and Findings}

In analysing the data, I follow Willig's six stages of Foucauldian discourse analysis. However, for reasons of space, related stages will be combined. Stages 1 and 2 will be discussed together, as will stages 4 and 5 .

\subsubsection{Stages 1 and 2: Parental discourses and the discursive construction of ADHD.}

The first stage involves identifying all the references, whether explicit or implicit, of the discursive object constructed in the text (Willig, 2008). Stage 2 locates the different constructions of the discursive object within wider discourses (Willig, 2008).

The first discursive construction that emerges is that of ADHD symptoms as normal childhood behaviors that did not raise any red flag for parents initially. For example: 
I told myself their behavior [her three children] was like other children, like us when we were at their age; it is normal behavior. (Sara)

I did not notice, I thought these behaviors were typical childhood behaviors, I did not notice that my child [her youngest child] was unlike the other children. I never noticed. (Noof)

Parents' judged their children's behavior as typical, regardless of the number of children in the family, or their order in the family, or the parents' level of education (Sara had only elementary education while Noof is a professor of early childhood education).

Parents only took action when their children's behavior was pointed out as problematic by someone else - a doctor (who might be visited for another reason, like flu or speech delay), or a teacher or relative:

The doctor noticed that she does not look at him or reach out to the things on his desk and became skeptical and said there is something else than the flu. (Farah)

The problem started with the school. The teachers noticed that she cannot focus, or write the alphabet letters. (Sara)

My mother-in-law is the one who noticed [his behavior] and advised me to take him to a doctor. (Noof)

Having been alerted by others, parents no longer considered the behavior of their ADHD child or children normal; they all seemed ready to pursue the matter further. All parents opted for the religious practice of reading the Quran over the child in order to detect the evil eye, or demonic possession -which were thought to be credible reasons for the children's symptoms. Three of the parents read the Quran over the child themselves:

I read [special Quranic verses used for detect/protect from the evil eye] on her by myself. I felt skeptical because doctors did not know what causes ADHD. (Rose) 
The four other parents took their children to one or more clerics to perform this Quranic ritual:

I took her to two clerics, one in Riyadh and one in Jeddah ... He read [the Quran] over her, but excluded the evil eye or black magic [as causes for her symptoms]. $\mathrm{He}$ said it is just a medical thing. (Farah)

I tried a number of clerics. One of them told me your son is possessed by demons because [Noof laughed at this point] my son slept when he read on him. Another cleric told me my child had the evil eye since I was pregnant. (Noof)

Within this cultural context, these parents considered the possibility that ADHD could be the result of a supernatural phenomenon, and that one legitimate treatment or approach could be a religious ritual. It is worth noting that Noof, who was highly educated, still thought of visiting several clerics. Clearly social class as indicated by education was no barrier to acceptance of the evil eye as a real force capable of causing ADHD symptoms, and therefore seeking advice from religious authorities.

However, all the parents also turned to medical authorities (including those who had consulted clerics). For three parents, diagnosis was relatively straightforward and accepted by the parents, who complied with the recommended treatment. For the others, getting a diagnosis was more time-consuming, more than one doctor was involved, and their diagnoses differed. But Rama and Rose fully accepted the ADHD label and medications:

I was afraid of the idea of medications, but I noticed her symptoms had gotten worse ... I took her to a psychiatrist ... he asked me number of questions about her history and what we noticed about her. He said she had ADHD based on only that one session... He prescribed Risperidone and two other drugs to help her focus... I knew Risperidone ${ }^{1}$ because her cousin took it for his ADHD... I gave her the medications right away. (Rama)

\footnotetext{
${ }^{1}$ Risperidone is used to treat schizophrenia and bipolar disorder (WebMD, 2018).
} 
The doctor saw her, asked me and her father about her and then said it is obvious she has ADHD... He asked us if we agreed to give her the medication. We said yes. As long as an expert recommends it, we will accept it right away. (Rose)

All the parents now constructed their children's symptoms as something requiring an opinion from a medical authority. But the medical professionals did not always seem to conduct a rigorous or standardized diagnostic procedure. For example, according to DSM-5 (2013), a second visit, or input from other sources such as teachers should have been sought. Nevertheless, three parents accepted the ADHD label and the medications recommended by the 'expert', even when he or she did not know what caused ADHD:

I have been following up with the genetic diseases clinic, but so far, the causes have not been discovered yet. The consultant said the ADHD diagnosis is not wrong but the reasons that cause it are unclear. It is like, if you have fever, what is causing the fever? That's how he explained it. (Rose)

Four parents had more challenging experiences with medical authorities. They not only resisted the doctors' conclusions and treatments, but also critiqued the medical account as unstable, unconvincing, and irrelevant. The doctor Fatimah visited to ascertain the reasons behind a speech delay of her son, who was nearly three years old, did seem to be more methodical in his assessment. Yet Fatimah did not accept his conclusion:

The doctor did inclusive medical testing, but I was not convinced by the result; yes, he is an active boy, but he does not have ADHD. The doctor said my son did not need medications now, but also said if his symptoms got worse we will have to prescribe medications for him. I do not want to give my son medications (Fatimah)

I think the doctors themselves do not know. They did not get to the real problem; each doctor has an opinion... We gave them the medications, but it did not help them. They sat calmly but in a very bad mood. It is like a man whose brain is very active and 
we restrained him by using the meds! This is not a solution ... we stopped giving them drugs. (Salem, the sole father interviewed). ${ }^{2}$

I truly believe it is medical flaws ... The problem, I think, in Saudi, is that doctors give you the whole package [the diagnosis results] in half an hour. (Noof). ${ }^{3}$

When talking about the causes of ADHD, six parents drew upon the social environment account:

The main cause of ADHD is TV - children's music channels, which I feel takes the child away from the world he lives in. In the past, when my son cried and I was busy, I let him watch these channels until I finished my work, which was about $50 \%$ of his day ... It is our fault we did not interact with him as much as we should. Now, I turn the TV off completely. (Fatimah)

The cause could have been when I was pregnant with him - my psychology was very bad. During my pregnancy, my husband and I were thinking of getting a divorce. (Noof)

Here, key social environmental experiences included early parental behavior, including their psychological state and the possibility that they neglected their child during this period.

All parents drew upon the religious discourse, using terms such as "thank God for this (the child's condition)", "God willing, my child will improve". As part of the religious discourse they saw ADHD as divinely sent:

ADHD is a problem sent from God ... We ask God to help us ... if I were not a believer I would run away; it is a very difficult situation. (Salem, the father of three children diagnosed with ADHD)

\footnotetext{
${ }^{2}$ Salem whose three children all had ADHD-type behavioral symptoms. His oldest child received a different diagnosis from different doctors - ADHD or mental retardation. According to him, the psychologist from the Ministry of Education did an IQ test and concluded that the child is 'mentally retarded'. This term is still used in Saudi Arabia.

${ }^{3}$ Noof whose child received a series of diagnoses from different doctors: autism, then ADHD with mild speech delay, then a doctor advised her that it might be not ADHD but another disorder.
} 
Maybe God gave me him so I could modify my own behaviors. I always love perfect things, my children have to have full marks in school, I have to have the best work evaluation, etc. Now God has sent me a message through my son: no, you do not have a perfect home life and you still have to be thankful for it. (Noof)

\subsubsection{Stage 3: Action orientation.}

This stage examines the outcomes and implications of constructing the discursive object in a particular way (Willig, 2008). By initially constructing ADHD as consisting of normal childhood behaviors, parents might be avoiding being blamed for the subjective nature of their own parenting role. Thus, at least in speaking of their initial perceptions, they referred to ADHD symptoms as 'normal', 'typical', 'like other children, like us when we were at their age'. This construction avoids any reference to or blame for the failing to suspect ADHD at an early stage and explains their lack of action at that stage.

Once they accepted there was a problem, all the parents were quick to accept a degree of blame for the child's problems. They then used another discursive technique to emphasize that the child was well cared for: they adopted a range of approaches: supernatural/religious, medical, and social environment. They consulted specialists from each different approach, often simultaneously. Mobilizing the 'supernatural' discourse, they wondered whether supernatural forces could mimic or cause the symptoms of medical conditions. They accepted that religious healers might have been able to learn, through reading verses from the Quran over the child, whether the child had a purely medical condition or whether it might be caused by supernatural forces. Subsequently, as in the accounts cited previously, one parent dismissed or minimized the importance of these clerical pronouncements.

Drawing upon the medical discourse, they took responsibility for following through on their children's symptoms with medical professionals; this, too, enabled them to construct themselves as active agents in the managements of their children symptoms. When they did not fully accept or comply with the medical professionals' 
instructions, this resistance constructed them as victims of medical flaws or inadequacies, with parents as the real experts who are able to understand their children.

Looking at these early years in retrospect could allow them to regain control over the 'wrongful' early practices that they engaged in (however innocently or unavoidably, because of work/personal pressures), when they still thought their children were 'typical'. Thus, they actively sought treatment, perhaps from several sources, dedicating more time to the child with ADHD, and eliminating potentially harmful influences (such as TV) from their homes.

\subsubsection{Stages 4 and 5: Positioning and practice.}

Stage 4 examines the subject positions offered by constructions of the discursive objects (Willig, 2008). Stage 5 outlines the possibilities for action contained within discursive constructions.

The findings emerging from the previous stages suggest that by constructing ADHD initially as consisting of merely normal childhood behaviors, parents were positioning themselves as inexperienced parents who made the best judgment they could, based on their own experience. Yet, motivated by religious, social, educational, or medical discourses, parents moved on and acknowledged their ignorance (and in some cases, neglect), accepting that they must now do something about it. This opened up opportunities to start taking action as the primary subjects responsible for 'fixing' their children's behavior. The participants started by negotiating the reality of the child's condition by considering ADHD, either simultaneously or in relatively quick succession, within supernatural-religious, medical and social environment contexts, each of which strengthened the parents' identity as 'active' parents - parents who had to endure great stress in dealing with their children, society's treatment of them, and in terms of the difficulty of getting help - who were doing everything they could to understand and fix their children's behavior.

Subscribing to the social environment account, Noof admitted to some early mistakes she felt she had made: 
My son also suffers from environmental neglect. From the time I gave birth to him until he was one year and nine months old, he was watching Touoor Aljanah [children's music channel] without any interaction with me or the nanny, and we did not take him out with the family all week long. He has ADHD tendencies and what we did to him has worsened it. (Noof)

Some parents followed the supernatural/religious and medical recommendations simultaneously. Medications prescribed to treat serious disorders such as schizophrenia or dementia were recommended by doctors, as shown below. These medications, especially Risperidone, were mentioned by all as treatments for ADHD.

Apart from reading verses from the Quran over the child, some clerics offered further treatments such as herbal mixes or creams. Most parents followed both religious and medical approaches, positioning themselves in both contexts in the traditional hierarchy of power as passive parents seeking help from authoritative, knowledgeable experts:

The psychologist told me that she has ADHD with Autism and prescribed Tanakan ${ }^{4}$, Risperidone, calcium tablets, and B12 injections... It was not easy for me to find some of these drugs, so I ordered them online from Egypt and France... The doctor advised me to work on both sides: medications and behavioral interventions. When I took her to a cleric who is famous for helping children with ADHD in Jeddah, he gave me a herbal mix and a cream to strengthen her feet. He asked me does she take Risperidone? I said yes, he said continue, do not stop it and give her the herbal mix with it. (Farah)

The doctor prescribed medication for her, but said this medication is not a cure, we use it to make her calm so she can focus. The real treatment is in behavioral therapy...We suffered because we do not have behavioral therapy centers in Alsulayyil. We go to Riyadh to [ a behavioral center] in school holidays. (Rose)

\footnotetext{
${ }^{4}$ Tanakan is used to treat memory disorders such as dementia and Alzheimer's disease (WebMD, 2018).
} 
Other parents used the knowledge gained in such encounters as tools to reverse and resist the hierarchy of power, positioning themselves as the real experts and the professionals as ignorant:

I believe the doctors do not know. We are trying to work with the children from home. We reinforce them by giving them money when they do desirable behaviors. (Salem, the father of the three ADHD children)

I feel tired, tired, tired. I got to a point when I searched online on the British Ministry of Health website to see what kinds of medications British parents use for their children. I read British and Canadian parents' experiences with medications and I evaluated whether their kids' behavior seemed similar to my son's behavior. If so, I took a note of the medication name, then went to the doctor and I asked him to prescribe it to my son ... I became the one who diagnosed my son ... if the mother has a different opinion than the doctor, it is her right! We have to trust our motherhood. (Noof)

Medical authorities also recommended behavioral therapies. All parents accepted this type of treatment but voiced some of the obstacles they encountered, such as the availability of behavioral centers, the high cost of such sessions, the time involved, and the questionable expertise of practitioners. This led some of the parents to try behavioral modification practices themselves by following recommendations on social media or YouTube videos:

I could not afford to pay for behavioral sessions. I watch behavioral exercises on YouTube videos, I communicate via social media with specialists, other mothers who have children with ADHD, I purchased games that I saw on YouTube that helps with attention. (Farah)

The behavioral center gave him a package of 14 sessions, which I feel he benefited from more than [treatment from] the doctor. (Fatimah)

As the result of their challenging, difficult experiences, and in the traditional religious context in which they had always lived, some parents drew upon discourses portraying ADHD as an affliction from God. This discourse functioned as a coping 
mechanism, alleviating the burden of feeling alone with their child's problem - instead, they feel comforted by having inspiration and help from God. As believers, their duty then becomes to accept and address this condition with patience, and to look ahead to the rewards of the afterlife:

The fact that there is life after makes me patient. We are doing our best to give him what he needs ... I once read an article saying that our kids are a blessing from God. Thank God for everything. (Noof)

\subsubsection{Stages 6: Subjectivity.}

The last stage in the analysis explores the relationship between discourse and subjectivity. As Willig (2008) puts it, 'Discourses make available certain ways of seeing the world and certain ways of being in the world,' (p.154), giving meaning to our social and psychological realities. This final stage is concerned with the effect of subject positions on the subject's thoughts, feelings, and experiences.

Internalizing the discourse of active parents who take action at 'fixing' the ADHD child's behavior, gives rise to difficult feelings: fear of the future, stress over the urgency of the task, and loss of control:

Thinking about the future disturbs me. What will happen when they grow up and get married? Are they going to have children like them [with ADHD]? ... I am afraid of the future, the problems will increase, what am I going to do when they grow up, how am I going to embrace them when people are rejecting them. ADHD is more like a bat: it is neither a bird nor an animal. We do an injustice to our children whether we place them with sick people, or normal people. (Salem, the father)

I think about the future. I am afraid that as she grows up she will not be a normal child. I am afraid that if I get pregnant I will have another child like her. (Farah)

I think if we did not intervene early, this might make the child less intelligent than her peers. We must be aware of the time and start intervening. (Rama)

Being an active parent to a child with ADHD can also involve feelings of guilt, which is manifested in the acknowledgement by some participants of missing the early 
signs of ADHD, and possibly an element of neglect in the early years. As Fatimah said, ADHD was her 'fault' because she did not interact with her child at an early age; for Noof, 'What we did to him has worsened [ADHD]'.

Having a child with ADHD can also prompt feelings of distress. These often arise from the way parents are treated by clerics, teachers or doctors, as well as their own families and friends:

We suffered from teachers, doctors, and the high cost of services ...we go back and forth between home and school [to solve the problems they cause] ... Our relatives tell me to come and visit but do not bring your kids with you... The teachers do not want my children to be in the school and when we move them to another school, the old teachers tell the new ones their opinions before my children even start in the new school. (Salem, the father).

My in-laws and society put a lot of pressure on me. The way they look at my child, they say she will not be able to study in typical schools, she will not be able to get married. People ask, what is wrong with your daughter? Why does she act like this? Show her what she should do, your child is sick, she has jinn [evil spirits], there is no cure. Sometimes I explain to them, sometimes I do not. (Farah)

There are many shocks I have encountered: my son's doctors, his teachers who humiliate me, the fact that I am suffering because I do not have enough money to fix him. Imagine your life is flying by and you cannot do anything, I brought in people [behavioral/speech therapists]. I do not know if they were really specialists or not, but I had to, and you have other children, a husband and [other responsibilities] to take care of. (Noof)

\section{Discussion}

Although previous qualitative and discursive studies have identified parental discourses regarding childhood ADHD, I am not aware of any Middle Eastern/North African research that has focused in depth on parental discourses. 
This study explored experiences of ADHD among a small sample of Saudi parents of children with ADHD. While not claiming to be representative of all Saudi parental experiences of ADHD, these accounts do convey the subjective world of the participants and the role of ADHD discourses. The discourse analysis carried out here shows how these parents made sense of their child's behavior pre-and post-diagnosis, constructing four main discourses in the process: normal behavior (pre-diagnosis), supernatural/religious, medical, and social environment (post-diagnosis).

Pre-diagnosis, participants did not objectify their children's behavior as different or deviant: this emerged in the discourses of both professionals and family members in which these behaviors were identified as problematic within a medical, educational, or social context. Contemporary schooling demands, such as the pressure to read and write (and the earlier or younger the better), and crowding of the curriculum have been recognized in Western literature as factors contributing to ADHD referrals (Graham, 2007).

Society's expectations of orderly behavior in children is reflected in the scientific discourse, which is encapsulated in the APA's DSM (describing the criteria and duration of symptoms indicating a diagnosis of ADHD). Teachers are expected to monitor and observe students for possible symptoms, extending the clinical gaze, as Foucault (1975) calls it, beyond medical experts to teachers. This process operates in a multi-directional manner to the point of surveillance over the supervisors themselves. Teachers are often the first to suggest a diagnosis of ADHD (Iudici et al., 2014).

Danforth and Navarro (2001) note that 'medical discourse ... is so dominant that language users have little choice but to contend with it in some fashion, whether they appropriate the discourse with reflexive acceptance, mild modification, or dramatic resistance' (p.173). In the context of ADHD, this allows the medical discourse to become the 'regime of truth' (Foucault, 1977) against which childhood itself is judged.

Saudi parents are engaged in similar medical accounts to those circulating in Western countries. In Saudi social media, namely Twitter, there are illustrations of medical discourse (analyzed in Alharbi, 2017). In the present study, the medical 
account is invoked within a context of ambiguity and resistance, especially when the presentation of ADHD is severe or present with comorbid 'disorders'. Even when a medical diagnosis has been made, its accuracy, causation and medical treatments might still be resisted by parents. For these parents, ADHD is not a sufficiently well-defined medical entity but rather a set of dysfunctional signs (Iudici et al. 2014).

Discourse analysis emphasises that understandings of ADHD, including its causes, emerge within a wider context of misconceptions and uncertainty among Saudi parents. Early neglect, parental preoccupations with other problems, the evil eye, children's music TV channels were all pointed out as contributors to ADHD symptoms, whereas a heredity discourse was almost absent (or mentioned only with uncertainty).

Saudi parents also viewed ADHD symptoms as an effect of supernatural possession. Forces such as 'jinn' and the evil eye are part of Islamic teaching (AlHabeeb, 2003), including many Quranic references, hence are an enduring and integral part of Saudi society. Supernatural beliefs influenced these parental understandings of dysfunctional behaviors in their children.

Parental beliefs regarding the causes of ADHD influence the treatment practices they favor (Yeh et al., 2005); in this study, all participants considered the possibility of demonic possession and tried Quranic readings. Four participants asked religious leaders to conduct this ritual and three did the readings themselves.

But although supernatural forces were considered a potential cause of their children's symptoms, this did not prevent these parents from seeking help from other (non-religious) authorities. This contradicts the conclusions of Yeh et al. (2005) - that etiological beliefs involving spiritual foundations are associated with a decreased likelihood of mental health service use.

All participants interpreted ADHD as an affliction from God, reflecting the Muslim belief that every life episode or challenge comes from God (Ismail et al., 2005), including both illness and cure (Alrubh, 2016). So for these parents, their perception of ADHD was shaped and supported by religious doctrine. Religious belief was a coping 
strategy, alleviating the stress of raising an ADHD child. As Johnson (2009) notes, religious beliefs can involve positive self-evaluations (God chose us), notions of control (God will help us in difficult times), and optimism about the future (God has a plan; Heaven awaits). It helped these parents to accept ADHD as God's will, and it seemed to strengthen their motivation to help their children.

All the participants in this research were influenced by a combination of medical, social, and religious discourses in their attempts to make sense of their children's symptoms. In Foucauldian terms, what is at stake here is that children with ADHD and even parents themselves are placed under close surveillance in the name of the children's wellbeing, and their capacity to fit into society. This places a heavy responsibility on parents, with outcomes for the children themselves uncertain, particularly in a society which is still learning to deal with ADHD-type behavior. Even in the West, where diagnosis and debate regarding ADHD has been a major theme, the pressures on parents and children are clear:

Due to their dependency upon the adult world for everything from basic sustenance to education and recreation, children are especially subject to the social ramifications of the ADHD diagnosis. Through the eyes of their educators, clinicians, and parents, the ADHD child's world requires regulation to promote the "management" of his/her disorder. Invariably, the active agents in this management are the authority figures surrounding ADHD children. In applying the ADHD mental disorder label to a child, adults take on the responsibility for structuring the child's life to meet the perceived treatment requirements in conjunction with the diagnosis (Rafalovich, 2001, p.373).

The one participating father in this study expressed the same responsibility as the participating mothers, in terms of internalizing the discourse of caring for his children's behavior. A Saudi study of childhood epilepsy similarly found that fathers were significantly involved in caring for their children with epilepsy. Of course, only one father participated in this ADHD study; future research should consult more Saudi 
fathers of ADHD-diagnosed children to get a wider view of fathers' experiences and degrees of engagement with their children.

Given that as ADHD is not a homogenous disorder (Taylor, 2009) parents' experiences may vary, especially when associated with different subtypes of ADHD or the presence of co-morbid disorders, and depending on the diagnosis, treatment, school context, and course of action followed by parents. Nevertheless, participating parents of ADHD children often experienced feelings of fear, guilt and psychological distress. These negative feelings are well documented in the literature (e.g. Cappe et al., 2017; Narkunam et al., 2014). Findings from the present study add to the scarce body of Saudi literature on this topic, and point to a need for more research into how these apparently problematic behavioral symptoms in children are understood, diagnosed and treated, how families experience these processes, and the discourses that shape the phenomenon of ADHD.

This paper argues that Saudi parents' discourses regarding ADHD are not only linked to diagnostic ambiguity, but also intertwine with the wider dynamics of modern society, including the power relations inherent in religious, medical, educational, and social contexts and how these impact on children's mental health. These factors increase surveillance of the child experiencing ADHD-type symptoms, alongside his or her parents. In this sense, the ADHD phenomenon in Saudi society has become a channel for competing parental, social, and educational demands-to 'naturalize' the child with ADHD in order to 'fit' well into society. 


\section{References}

- $\quad$ Abdur-Rahim, F. E. A., Al-Hamad, A. R., Chaleby, K., \& Al-Subaie, A. (1996). A survey of a child psychiatry clinic in a teaching hospital in Saudi Arabia clinical profile and cross-cultural comparison. Saudi Medical Journal, 17(1), $36-41$.

- Alamiri, F., \& Faulkner, M. (2010). Challenging Gifted Children and the Phenomenon of AD/HD: A Qualitative Study of Teachers' and Parents' Perceptions in a Saudi Arabian Primary School. Australasian Journal of Gifted Education, 19(1), 6.

- Al-Habeeb, T. a. (2003). A pilot study of faith healers' views on evil eye, jinn possession, and magic in the kingdom of Saudi Arabia. Journal of Family \& Community Medicine, 10(3), 31-8.

- Alharbi, R. S. (2017). Attention-Deficit Hyperactivity Disorder (ADHD) Discourses in Saudi Arabia (Unpublished doctoral dissertation). University of Ottawa, Canada.

- Alrubh, F. S. (2016). Saudi Arabian mothers of children with sickle cell disease as givers of social support. Electronic Theses and Dissertations. University of Northern Iowa, US.

- $\quad$ Armstrong, T. (2017). The Myth of the ADHD Child: 101 Ways to Improve Your Child's Behavior and Attention Span Without Drugs, Labels, Or Coercion. Penguin.

- Arnsten, A. F. (2009). The emerging neurobiology of attention deficit hyperactivity disorder: the key role of the prefrontal association cortex. The Journal of pediatrics, 154(5), I.

- Association, A. P. (2013). Diagnostic and Statistical Manual of Mental Disorders. DSM-5. Arlington, VA: American Psychiatric Publishing.

- Baxter, J. (2002). Competing discourses in the classroom: A post-structuralist discourse analysis of girls' and boys' speech in public contexts. Discourse and Society, 13(6), 827-842. 


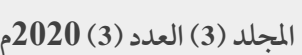

- $\quad$ Cappe, E., Bolduc, M., Rougé, M.-C., Saiag, M.-C., \& Delorme, R. (2017).

Quality of life, psychological characteristics, and adjustment in parents of children with Attention-Deficit/Hyperactivity Disorder. Quality of Life Research, 26(5), 1283-1294.

- Cione, G. F., Coleburn, L. A., Fertuck, E. A., \& Fraenkel, P. (2011). Psychodynamic play therapy with a six-year-old African American boy diagnosed with ADHD. Journal of Infant, Child and Adolescent Psychotherapy, 10, 130-143.

- $\quad$ Conrad, P., \& Schneider, J. W. (2010). Deviance and medicalization: From badness to sickness. Temple University Press.

- $\quad$ Conrad, P., and Bergey, M., R. (2014). The impending globalization of ADHD: Notes on the expansion and growth of a medicalized disorder. Social Science and Medicine, 122, 31-43.

- $\quad$ Conway, F. (2012). Psychodynamic psychotherapy of ADHD: A review of the literature. Psychotherapy, 49(3), 404.

- Danforth, S., \& Navarro, V. (2001). Hyper talk: Sampling the social construction of ADHD in everyday language. Anthropology \& education quarterly, 32(2), 167-190.

- $\quad$ Dreyfus, H. L. and Rabinow, P. (1982). Michel Foucault: Beyond structuralism and hermeneutics. Wheatsheaf, London: Harvester.

- Foucault, M. (1972). The Archaeology of Knowledge: Translated from the French by AM Sheridan Smith. Pantheon Books.

- Foucault, M. (1975). 2003. Abnormal: Lectures at the Collège De France, 19741975.

- Foucault, M. (1977). Discipline and punish: The birth of the prison (A. Sheridan, Trans.). London: Penguin Books.

- Foucault, M. (1994). The art of telling the truth. Critique and power: Recasting the Foucault/Habermas debate, 139-148. 
- $\quad$ Ghanizadeh, A. (2007). Educating and counseling of parents of children with attention-deficit hyperactivity disorder. Patient Education and Counseling, 68(1), 23-28.

- Gidwani, P., Opitz, G., \& Perrin, J., (2006). Mothers' views on hyperactivity: A cross-cultural perspective. Journal of Developmental and Behavioral Pediatrics, 27, 121-126.

- Gilmore, K. (2000). A psychoanalytic perspective on attention-deficit/ hyperactivity disorder. Journal of the American Psychoanalytic Association, 48, 1259-1293.

- Gilmore, K. (2002). Diagnosis, dynamics, and development: Considerations in the psychoanalytic assessment of children with AD/HD. Psychoanalytic Inquiry, 22, 372-390.

- Graham, L. J. (2007). (Re)Visioning the Centre: education reform and the 'ideal' citizen of the future. Educational Philosophy and Theory, 39(2), 197-215.

- Hammond, M. (2008). Twenty-two Lenses for a Single Diagnosis: An Ethnography of ADHD, ProQuest Dissertations and Theses.

- Hansen, J. H. (2014). Take a chill pill: a cultural history of Attention Deficit/Hyperactivity Disorder, ProQuest Dissertations and Theses.

- Hinshaw, S. P., \& Scheffler, R. M. (2014). The ADHD explosion: Myths, medication, money, and today's push for performance. Oxford University Press.

- Hinshaw, S., Scheffler, R., Fulton, B., Aase, H., Banaschewski, T., Cheng, W., and Sergeant, J. A. (2011). International variation in treatment procedures for ADHD: social context and recent trends. Psychiatric Services, 62(5), 459-464.

- Ismail, H., Wright, J., Rhodes, P., \& Small, N. (2005). Religious beliefs about causes and treatment of epilepsy. Br J Gen Pract, 55(510), 26-31.

- Iudici, A., Faccio, E., Belloni, E., \& Costa, N. (2014). The Use of the ADHD Diagnostic Label: What Implications Exist for Children and Their Families? Procedia-Social and Behavioral Sciences, 122, 506-509. 
- Jenahi, E., Khalil, M. S., \& Bella, H. (2012). Prevalence of attention deficit hyperactivity symptoms in female schoolchildren in Saudi Arabia. Ann Saudi Med, 32(5), 462-8.

- Johnson, D. D. (2009). God would be a costly accident: Supernatural beliefs as adaptive. Behavioral and Brain Sciences, 32(6), 523-524.

- Jones, B. (2011). The reality-sampling deficit and ADHD: Indication for an active technique. Journal of Infant, Child and Adolescent Psychotherapy, 10, 73-86.

- Jones, B., \& Allison, E. (2010). An integrated theory for attention-deficit hyperactivity disorder [ADHD]. Psychoanalytic Psychotherapy, 24, 279295.

- $\quad$ Ladnier, R. D., \& Massanari, A. E. (2000). Treating ADHD as attachment deficit hyperactivity disorder. Handbook of attachment interventions, 27-65.

- Lawton, K., Gerdes, E., Haack, A., \& Schneider, C. (2014). Acculturation, Cultural Values, and Latino Parental Beliefs About the Etiology of ADHD. Administration and Policy in Mental Health and Mental Health Services Research, 41(2), 189-204.

- $\quad$ Leuzinger-Bohleber, M., Laezer, K., Pfenning-Meerkoetter, N., Fischmann, T., Wolff, A., \& Green, J. (2011). Psychoanalytic Treatment of ADHD Children in the Frame of Two Extra clinical Studies: The Frankfurt Prevention Study and the EVA Study. Journal of Infant, Child, and Adolescent Psychotherapy, $10(1), 32-50$.

- $\quad$ Maniadaki, K., Sonuga-Barke, E., Kakouros, E., \& Karaba, R. (2007). Parental beliefs about the nature of ADHD behaviours and their relationship to referral intentions in preschool children. Child: care, health and development, 33(2), 188-195.

- Mannuzza, S., Klein, R. G., and Moulton III, J. L. (2003). Persistence of attention deficit/hyperactivity disorder into adulthood: what have we learned from the prospective follow up studies?. Journal of attention disorders, 7(2), 93-100. 
- $\quad$ McIntyre, R., \& Hennessy, E. (2012). 'He's just enthusiastic. Is that such a bad thing?' Experiences of parents of children with Attention Deficit Hyperactivity Disorder. Emotional and Behavioural Difficulties, 17(1), 6582.

- $\quad$ Narkunam, N., Hashim, A. H., Sachdev, M. K., Pillai, S. K., \& Ng, C. G. (2014). Stress among parents of children with attention deficit hyperactivity disorder, a Malaysian experience. Asia-Pacific Psychiatry, 6(2), 207-216. https://doi.org/10.1111/j.1758-5872.2012.00216.x

- $\quad$ Nigg, J. T. (2006). What Causes ADHD? New York Guilford Publications.

- $\quad$ Parker, I. (n.d.). Discourse dynamics: Critical analysis for social and individual psychology. London; New York: Routledge.

- $\quad$ Polanczyk, G. V., Willcutt, E. G., Salum, G. A., Kieling, C., \& Rohde, L. A. (2014). ADHD prevalence estimates across three decades: an updated systematic review and meta-regression analysis. International journal of epidemiology, 43(2), 434-442.

- $\quad$ Polanczyk, G., de Lima, M. S., Horta, B. L., Biederman, J., and Rohde, L. A. (2007). The worldwide prevalence of ADHD: a systematic review and metaregression analysis. American journal of psychiatry, 164(6), 942-948.

- $\quad$ Rafalovich, A. (2001). Disciplining domesticity: Framing the ADHD parent and child. The Sociological Quarterly, 42(3), 373-393.

- $\quad$ Said, E. W. (1978). The problem of textuality: Two exemplary positions. Critical Inquiry, 4(4), 673-714.

- $\quad$ Saul, R. (2014). ADHD does not exist: The truth about attention deficit and hyperactivity disorder. Harper Collins.

- $\quad$ Southall, A. (2007). The other side of ADHD: Attention deficit hyperactivity disorder exposed and explained. Radcliffe Publishing.

- Taleb, R., \& Farheen, A. (2013). a Descriptive Study of Attention Deficit Hyperactivity Disorder in Sabia City, Saudi Arabia. Ijcrr, 5(11), 36-41. 


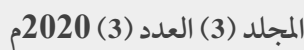

- Tamboukou, M. (1999). Writing Genealogies: an exploration of Foucault's strategies for doing research. Discourse: studies in the cultural politics of education, 20(2), 201-217.

- Taylor, E. (2009). Developing ADHD. Journal of Child Psychology and Psychiatry, 50(1-2), 126-132.

- $\quad$ Timimi, S., and Taylor, E. (2004). ADHD is best understood as a cultural construct. The British Journal of Psychiatry, 184(1), 8-9.

- $\quad$ Tzang, R. F., Chang, Y. C., \& Liu, S. I. (2009). The association between children's ADHD subtype and parenting stress and parental symptoms. International Journal of Psychiatry in Clinical Practice, 13(4), 318-325.

- Visser, J., and Jehan, Z. (2009). ADHD: A scientific fact or a factual opinion? A critique of the veracity of Attention Deficit Hyperactivity Disorder. Emotional and behavioural difficulties, 14(2), 127-140.

- Widener, A. J. (1998). Beyond Ritalin: The importance of therapeutic work with parents and children diagnosed ADD/ADHD. Journal of Child Psychotherapy, 24(2), 267-281.

- Willig, C. (2008) Introducing qualitative research in Psychology. 2nd ed. Berkshire: Open University Press.

- $\quad$ Yeh, M., McCabe, K., Hough, R. L., Lau, A., Fakhry, F., \& Garland, A. (2005). Why bother with beliefs? Examining relationships between race/ethnicity, parental beliefs about causes of child problems, and mental health service use. Journal of Consulting and Clinical Psychology, 73(5), 800.

- Zaki, R. A. (2013). Enhancement the Awareness of Family Caregivers Caring for their Children with Attention Deficit Hyperactivity Disorder of the General Administration of Intellectual Education Centers in the city of Abha. Journal of American Science, 8(9). 